\title{
Estudo da Interação de Uma Cooperativa Habitacional com a Socieda-
}

\author{
Study of the Interaction of a Cooperative Housing With Societyt
}

\begin{abstract}
Resumo
Com o intuito de compreender como se dá a interação das organizações cooperativas e de economia com a sociedade, e quais são os elementos que constituem essa integração, o presente artigo foi desenvolvido. Para isso, escolheu-se uma cooperativa habitacional. A pesquisa classifica-se como um estudo de caso qualitativo. A principal técnica de coleta de dados foi a entrevista semiestruturada, realizada com o Presidente, o Diretor Pedagógico e uma cooperada. Os resultados revelam que os princípios do cooperativismo estão enraizados nas atividades da cooperativa, principalmente os princípios da autogestão, livre adesão e o da educação. Apesar das diversas situações que a cooperativa passou como problemas de sustentabilidade financeira, os resultados mostraram que se vem criando e dedicando cada vez mais espaço dentro da sociedade para os ideais cooperativistas. Aderir à cooperativa mostra que é possível ter desenvolvimento pessoal e social, o que serve como impulso e motivação para expandir as atividades da cooperativa, para isso é necessário haver uma mudança na forma de pensar da sociedade para que o pensamento cooperativista e a forma de se organizar do cooperativismo possam ganhar espaço na vida das pessoas.
\end{abstract}

Palavras-chave: Cooperativismo; Cooperativa habitacional; Princípios cooperativistas; Desenvolvimento sustentável; Sociedade.

\begin{abstract}
The interaction between cooperative organizations and of solidarity economy and the society is the principal focus of this assignment, emphasizing the influence that this kind of cooperation gets, becoming a mechanism of transformation and social inclusion, in addiction, what these interactions are made of. For this, we chose a housing cooperative. This research is classified as qualitative case study, getting done through semi-structured interviews with the President, the Pedagogic Directory and a cooperating person. The results reveal that the cooperative principles are rooted in the activities of the cooperative, especially the principles of self-management, free membership and education. Although this organization had been in difficulties in its beginning, results demonstrated that society keeps opening space to the cooperativism ideals. Join the cooperative shows that it is possible to have personal and social development, which serves as the impetus and motivation to expand the activities of the cooperative, it is necessary to be a change in the mindset of society so that the cooperative thinking and the way of organize the cooperatives can gain space in people's lives.
\end{abstract}

Keywords: Cooperative; Housing cooperative; Cooperative principles; Sustainable development; Society.

Alan César Souza Maciel ${ }^{1}$, Yane Ágata Ribeiro Marcelino ${ }^{2}$, Amanda Bilibio ${ }^{3}$, Ana Paula Anziliero Hermes ${ }^{4}$, Diego Bilibio ${ }^{5}$ e Enise Barth-Teixeira ${ }^{6}$

${ }^{1}$ Universidade Federal da Fronteira Sul; Rua Raimundo Lusa, 310D, Ap. 301, Bairro Efapi, CEP: 36576-517; Chapecó, Santa

Catarina, Brasil - alancsmaciel@yahoo.com.br

2,3,4,5,6 Universidade Federal da Fronteira Sul; Chapecó, Brasil 


\section{Introdução}

$\mathrm{O}$ cooperativismo é tido como a forma ideal de organização. É o modelo socioeconômico que tem a capacidade de unir o desenvolvimento econômico e o bem-estar social. Tem como fundamento a união de pessoas e não o capital e segue os princípios da solidariedade, participação democrática, autonomia e independência (OCB, 2014).

O tema desenvolvido neste estudo é o Cooperativismo e Economia Solidária como Caminho para o Desenvolvimento Sustentável, e a organização objeto desta pesquisa foi a Cooperativa Habitacional Central do Brasil - Coohabras. E o problema de pesquisa é: como se evidencia a interação da cooperativa habitacional e a sociedade onde ela está inserida com base nos princípios do cooperativismo?

Dessa forma, o objetivo do presente artigo é entender a interação da cooperativa habitacional e a sociedade onde ela está inserida. A respeito disso, verificar quais são os elementos que constituem essa integração, tais como desenvolvimento econômico, social e ambiental e o que caracteriza um modelo cooperativista de organização social.

A Coohabras é uma cooperativa habitacional gerida coletivamente por seus associados, sendo dirigida pelo Novo Código Civil com a Lei 10.406/02 e pela Lei do Cooperativismo Lei 5.764/71. Atuando em boa parte do território nacional, busca auxiliar as famílias na conquista de seu imóvel próprio, priorizando as famílias com rendas inferiores, com até três salários mínimos.

A interação que existe entre as organizações cooperativas e a sociedade é o principal foco dessa pesquisa, sendo importante destacar a influência que essas formas de cooperação têm ao se tornarem mecanismos de transformação e inclusão social, pois como no caso da Coohabras além de proporcionar a moradia ao cooperado, também permite compreender todo o contexto que se encontra através do acesso a educação.

Diante do exposto, o desenvolvimento deste estudo possui grande relevância para o fornecimento de bases teóricas a fim de introduzir a compreensão de como o modelo cooperativista de organização vem realizandose no contexto econômico brasileiro, sua participação dentro dos diversos setores que integram a sociedade, a relevância que esse modelo se permite causa na área imobiliária e sua relação com a sociedade.

O presente trabalho está estruturado da seguinte forma: referencial teórico, abordando os temas de desenvolvimento sustentável, cooperação, cooperativismo e cooperativismo habitacional, posteriormente é descrita a metodologia utilizada, seguida pelos resultados e discussão, e por fim as considerações finais que também contemplam limitações e sugestões de estudos futuros.

\section{Referencial Teórico}

Os novos paradigmas para a sociedade do século 21 devem ter como base a ecologia, a finitude dos recursos naturais, os princípios da suficiência, da responsabilidade social e da solidariedade. Disso resultam imensos desafios à humanidade, em todos os níveis e campos da organização humana. Trata-se de um cenário de desafios à ciência, educação, política e economia (FRANTZ, 2012).

\subsection{Desenvolvimento Sustentável}

No contexto atual, é muito discutido um modo de vida que seja sustentável, que busque preservar os recursos naturais visando o futuro das próximas gerações. A notável fase de crescimento econômica dos países em desenvolvimento, o crescimento populacional, as indústrias, os veículos e o próprio consumismo dessa geração, além de tudo que está relacionado ao crescimento acaba por afetar o meio ambiente. O desenvolvimento é necessário, porém, é preciso promover um equilíbrio entre o progresso e o meio ambiente, ou seja, um desenvolvimento sustentável.

A preocupação com o desenvolvimento tem início nos anos 60, sendo que, no ano de 1972 Dennis L. Meadows juntamente com um grupo de pesquisadores do Clube de Roma publicaram a Tese sobre Limites de Crescimento, esse estudo concluía que, se os níveis de produção de alimentos, industrialização, exploração de recursos naturais e poluição fossem mantidos, em no máximo 100 anos o planeta atingiria seu limite de desenvolvimento, que acabaria por provocar a diminuição da capacidade de produção industrial e da população mundial. Ainda em 1972 ocorreu a Conferência de Estocolmo, na qual foram discutidos os riscos da degradação do meio ambiente. Para Meadows, a estabilidade econômica e ecologia, seriam alcançadas se houvesse o congelamento do crescimento populacional mundial e também do capital industrial, entretanto essa tese, sofreu muitas criticas, dentre elas a do premio Nobel em Economia, Solow (1973 e 1974) que criticava os resultados dos estudos do Clube de Roma, também Mahbub ul Haq (1976), ao levantar a tese de que os países do ocidente após um século de crescimento industrial fechariam esse caminho para o desenvolvimento dos países pobres (BRÜZEKE, 2009).

No ano de 1973 que o conceito de eco desenvolvimento foi usado pela primeira vez, pelo canadense Maurice Strong, como alternativa de política de desenvolvimento, onde seus princípios básicos foram formulados por Ignacy Sachs (ano de suas obras). Essa nova visão de desenvolvimento integra seis aspectos que deveriam guiar os caminhos do desenvolvimento, sendo eles: a) satisfação das necessidades básicas; b) a solidariedade com as gerações futuras; c) a participação da população envolvida; d) a preservação dos recursos naturais e do meio ambiente em geral; e) a elaboração de um sistema social, garantindo emprego, segurança social e respeito a outras culturas, e f) programas de educação. A teoria do eco desenvolvimento tinha relação, principalmente 
com regiões subdesenvolvidas, sendo que inicialmente se referiu às regiões rurais da África, Ásia e America Latina, envolvia assim uma critica a sociedade industrial e também a modernização industrial como forma de desenvolvimento das regiões periféricas.

Em uma reunião de Conferencia das Nações Unidas sobre Comércio-Desenvolvimento a (UNCTAD) e do Programa de Meio Ambiente das Nações Unidas (UNEP) em 1974, resultou na Declaração de Cocoyok que contribuiu também na discussão sobre o desenvolvimento e meio ambiente, a declaração afirmava que a pobreza gerava o desequilíbrio demográfico, onde a destruição ambiental também era consequência da pobreza devido à superutilização do solo e dos recursos vegetais, já os países industrializados contribuíam para problemas com o subdesenvolvimento por seu nível de consumo exagerado. Portanto, não há apenas um limite mínimo de recursos necessários para o bem-estar do individuo, mas também um limite máximo.

A Fundação Dag- Hammarskjöld com a participação de pesquisadores e políticos de 48 países elaborou um projeto, onde aprofundou as ideias de Cocoyok em seu relatório final. O Relatório Dag-Hammarskjöld aponta para a problemática do abuso de poder e sua interligação com a degradação ecológica, mostrando que o sistema colonial concentrava as terras melhores para uma minoria, levando a população pobre a usar solos menos apropriados, causando devastação ambiental. Tanto o relatório de Cocoyok quanto o de Dag-Hammarskjöld dividem o fato da sua rejeição ou omissão por parte dos governos dos países industrializados e dos cientistas políticos conservadores (BRÜZEKE, 2009).

O trabalho da Comissão Mundial da ONU sobre Meio Ambiente e o Desenvolvimento (UNCED), presidida por Gro Harlem Brundtland e Mansour Khalid, resultou no Relatório Brundtland em 1987, onde o termo "desenvolvimento sustentável" foi utilizado pela primeira vez.

Conforme a definição do Nosso Futuro Comum (CMMA, 1988, p. 46), citado por Mendes et al (2009, p.55): Desenvolvimento sustentável "é desenvolvimento que satisfaz as necessidades do presente sem comprometer a capacidade de as futuras gerações satisfazerem suas próprias necessidades". O relatório descreve as causas dos problemas socioeconômicos e ecológicos da sociedade global, destacando a interligação entre política, tecnologia, economia, sociedade e adverte ainda para uma nova postura ética e de responsabilidade dos membros da sociedade.

O relatório possui várias medidas a serem tomadas em nível de Estado nacional, que inclui, a limitação de crescimento populacional, garantia de alimentação a longo prazo, preservação dos ecossistemas e da biodiversidade, diminuição do consumo de energia e desenvolvimento de tecnologias que admitam o uso de fontes de energias renováveis, aumento da produção industrial em países não industrializados a partir de tecnologias ecológicas, controle de urbanização selvagem e integração entre campo e cidades menores, satisfação das necessidades básicas. Enquanto que em nível internacional as metas são, as organizações do desenvolvimento devem adotar a estratégia do desenvolvimento sustentável, a comunidade internacional deve proteger ecossistemas supranacionais como a Antártica, os oceanos, o espaço, guerras devem ser banidas, e a ONU deve implantar um programa de desenvolvimento sustentável. Este documento não possui as mesmas críticas a sociedade industrial dos anteriores e, sim, quer crescimento tanto dos países industrializados quanto dos não industrializados, e ainda ligando a superação da pobreza dos países subdesenvolvidos com o crescimento continuo dos países industrializados. O documento teve grande aceitação ao ser publicado. $\mathrm{O}$ conceito de desenvolvimento sustentável surgiu a partir dos estudos da Organização das Nações Unidas (ONU) sobre as mudanças climáticas, no início da década de 1970, como uma resposta à preocupação da humanidade, diante da crise ambiental e social que se abateu sobre o mundo desde a segunda metade do século passado (BRÜZEKE, 2009).

Gonçalves (2005), explica esse conceito como uma procura de conciliar a necessidade de desenvolvimento econômico da sociedade com a promoção do desenvolvimento social e com o respeito ao meio-ambiente, sendo esse tema indispensável nas discussões das mais diversas organizações, e nos mais diferentes níveis de organização da sociedade, como nas discussões diárias da sociedade sobre o desenvolvimento dos municípios e das regiões.

A Conferência das Nações Unidas sobre Meio Ambiente e Desenvolvimento (UNCED), no ano de 1992 na cidade do Rio de Janeiro, ainda que apresentasse um aumento no interesse mundial pelo futuro do planeta, a conferência não correspondeu às expectativas sobre ela, devido ao fato da delegação dos Estados Unidos ter sido a favor da eliminação de metas e cronogramas na limitação de emissão de CO2, além de que os Estados Unidos também não assinou a convenção sobre a proteção da biodiversidade.

A utopia do desenvolvimento sustentável tem a ver com a descoberta de meios e modos de evitar esses descarrilamentos. Mais do que isso: tem a ver com a invenção de meios e modos de fazer com que os efeitos do uso e da usura do oikos venham a confluir harmonicamente, não catastroficamente. Mas devem afluir à meta final ainda dentro do horizonte da finitude humana, ou já não teriam sentido (MENDES, 2009).

Para Brüseke (2009, p. 37):

Nas circunstâncias atuais, marcadas pela tentativa secular e pelo fracasso da industrialização não capitalista, o desdobramento de uma polêmica apontando deficiências parece mais fácil do que a reconstrução de alternativas teóricas e práticas do desenvolvimento. Governos e candidatos ao governo abraçam ainda com a coragem dos desorientados a ideia da modernização, sem perceber que o modelo da 
industrialização tardia é capaz de modernizar alguns centros ou setores da economia, mas incapaz de oferecer um modelo de desenvolvimento equilibrado da sociedade inteira.

A modernização, não acompanhada da intervenção do Estado racional e das correções partindo da sociedade civil, desestrutura a composição social, a economia territorial, e seu contexto ecológico. Por isso, necessitamos de uma perspectiva multidimensional, que envolva economia, ecologia e política ao mesmo tempo. Isso no fundo é o ponto de partida da teoria do desenvolvimento sustentável. Apesar da sua estrutura ainda inacabada, aponta este conceito na direção certa. Quem não quiser se perder no caminho precisa mais do que boa vontade, ou financiamento externo: precisa de ciência (BRÜSEKE, 2009).

\subsection{Cooperação}

De acordo com Frantz (2012, p. 83), a cooperação é entendida "como uma ação consciente e combinada entre indivíduos ou grupos associativos com vista a um determinado fim". O autor define a cooperação como "um processo social, embasado em relações associativas, na interação humana, pela qual um grupo de pessoas busca encontrar respostas e soluções para seus problemas comuns, realizar objetivos comuns, busca produzir resultados, mediante empreendimentos coletivos com interesses comuns".

Para Jesus e Tiriba (2003, p. 49), o termo cooperação tem "o significado semântico de ato de cooperar, ou operar simultaneamente, trabalhar em comum, colaborar, sinalizando, portanto, para um sentido de movimento coletivo, sempre em oposição à perspectiva individual e individualista. Enquanto ação, cooperação significa tomar parte de um empreendimento coletivo cujos resultados dependem da ação de cada um dos participantes".

Ao contrário do individualismo, a cooperação traduz a necessidade de alguém trabalhar com alguém para que ela ocorra. Em termos sociais, será necessária uma relação de soma, de agregação como ocorreu na evolução da humanidade (SEBRAE, 2009).

Frantz (2012, p. 60):

A cooperação é uma ação que decorre de um ato de vontade política de indivíduos que passam a se identificar como sujeitos e atores, a partir de necessidades ou interesses comuns, em um determinado contexto social. Passam a pensar e a agir de uma forma ordenada e esclarecida, associando-se na interação, com vistas à realização de seus objetivos. Normalmente, trata-se da afirmação de necessidades e interesses econômicos, no contexto do mercado, isto é, os associados buscam a valorização de seu trabalho.

De acordo com Costa (2007) citado por Lourenço et al (2013), não se pode confundir o ato de cooperar com o cooperativismo, pois enquanto o primeiro pode ser entendido como qualquer ato ou ação de colaborar com outras pessoas em qualquer formação socioeconômica, o segundo só pode ser entendido como um movimento social que procurou, através da associação, fugir de uma opressão social resultante de um determinado período histórico e de um determinado sistema, ou seja, o capitalismo concorrencial do século XIX.

O conceito de cooperação só tem utilidade se não for pensado abstratamente, isto é, tem pouco valor um suposto processo social de cooperação, considerado isoladamente ou desvinculado de um determinado contexto histórico-social. É como se a raiz comum das palavras cooperação e cooperativismo correspondesse na realidade uma espécie de vocação natural do ser humano, as cooperativas sendo apenas a expressão natural e decorrente daquela vocação humana e universal (RIOS, 2014).

O grande desafio da cooperação é a cultura, uma vez que nossa sociedade ainda é dominantemente competitiva, não privilegiando o aprendizado do trabalhar junto como forma de alcançar resultados (SEBRAE, 2014).

\subsection{Cooperativismo}

Na visão de Frantz (2012), é possível mudar o modelo capitalista de organização que a sociedade está sujeita através do cooperativismo. Esse, por sua vez, é um movimento que acontece ao redor do mundo todo, capaz de unir o desenvolvimento econômico com o bem estar das pessoas e necessita a colaboração e a associação de pessoas com os mesmos interesses e tem como principais referências a participação democrática, a solidariedade, a independência e a autonomia. $\mathrm{O}$ cooperativismo já faz parte das instituições, um bilhão de pessoas estão ligadas ao cooperativismo em todos os continentes (SICOOB BLUCREDI, 2013).

O Cooperativismo, no entendimento de Carvalho (2011) também tem seu marco histórico na revolução industrial, em função do uso do vapor como força motriz, sendo assim, resolveu reunir-se para detectar uma solução para manterem seu trabalho.

A classe operária influenciada por eles começa a procurar alternativas, surgindo em 1844 na Inglaterra a Sociedade dos Probos Pioneiros de Rochdale, a primeira cooperativa, fundada por 28 tecelões, o exemplo da cooperativa logo se espalhou pela Europa. (SICOOB BLUCREDI, 2013).

De acordo com a OCB (2014), o cooperativismo tem sete princípios básicos que são adotados e seguidos pelas cooperativas, são eles:

- Adesão voluntária e livre - as cooperativas são organizações voluntárias, abertas a todas as pessoas aptas a utilizar os seus serviços e assumir as responsabilidades como membros, sem discriminações de sexo, sociais, raciais, políticas e religiosas. 
- Gestão democrática - as cooperativas são organizações democráticas, controladas pelos seus membros, que participam ativamente na formulação das suas políticas e na tomada de decisões. Os homens e as mulheres, eleitos como representantes dos demais membros, são responsáveis perante estes.

- Participação econômica dos membros - os membros contribuem equitativamente para o capital das suas cooperativas e controlam-no democraticamente. Parte desse capital é, normalmente, propriedade comum da cooperativa. Os membros recebem, habitualmente, se houver, uma remuneração limitada ao capital integralizado, como condição de sua adesão.

- Autonomia e independência - as cooperativas são organizações autônomas, de ajuda mútua, controladas pelos seus membros. Se firmarem acordos com outras organizações, incluindo instituições públicas, ou recorrerem a capital externo, devem fazê-lo em condições que assegurem o controle democrático pelos seus membros e mantenham a autonomia da cooperativa.

- Educação, formação e informação - as cooperativas promovem a educação e a formação dos seus membros, dos representantes eleitos e dos trabalhadores, de forma que estes possam contribuir, eficazmente, para o desenvolvimento das suas cooperativas. Informam o público em geral, particularmente os jovens e os líderes de opinião, sobre a natureza e as vantagens da cooperação.

- Intercooperação - as cooperativas servem de forma mais eficaz aos seus membros e dão mais - força ao movimento cooperativo, trabalhando em conjunto, através das estruturas locais, regionais, nacionais e internacionais.

- Interesse pela comunidade - as cooperativas trabalham para o desenvolvimento sustentado das suas comunidades através de políticas aprovadas pelos membros.

Schmidt e Perius (2003) afirmam que, seguindo esses princípios, as cooperativas levam os seus valores a prática. Assim, o cooperativismo tem sido a resposta aos problemas impostos pela globalização. Um contrapeso, a concentração da riqueza, propulsor do desenvolvimento sustentável e gerador de emprego e renda.

Conforme o Brasil Cooperativo (2008), a primeira cooperativa Brasileira registrada, foi uma cooperativa de consumo criada no meio urbano em 1889, a Sociedade Cooperativa Econômica dos Funcionários Públicos de Ouro Preto. Em 1902 surgiram as cooperativas de crédito no Rio Grande do Sul, por iniciativa do padre suíço Theodor Amstad. E em 1906 nasceram e se desenvolveram as cooperativas no meio rural, idealizadas por produtores agropecuários.

A Organização das Cooperativas Brasileiras (OCB), criada em 2 de dezembro de 1969 e registrada em cartório no ano seguinte, sociedade civil e sem fins lucrativos, representante e defensora dos interesses cooperativistas nacional. (BRASIL COOPERATIVO, 2008).

De acordo com a Organização das Cooperativas Brasileiras (2014), nos dias de hoje existem mais de 6.500 cooperativas no Brasil, com 10 milhões de associados em treze setores da economia: agropecuário, educacional, de trabalho, produção, saúde, consumo, habitacional, mineração, transporte, turismo e lazer, infraestrutura, especiais e de crédito.

\subsection{Cooperativismo Habitacional}

De acordo com o artigo 981 da Lei no 10.406 , de 10 de janeiro de 2002 do novo Código Civil, as Cooperativas "celebram contrato de sociedade as pessoas que reciprocamente se obrigam a contribuir, com bens ou serviços, para o exercício de atividade econômica e a partilha, entre si, dos resultados". A saber disso, a cooperativa habitacional é uma modalidade de organização cooperativa que consiste em uma associação de pessoas com a formação gradativa de poupança conjunta, a obtenção de meios para a aquisição de um imóvel para a sua moradia, a um preço de custo (CASTELO, 1999).

O movimento cooperativista habitacional no Brasil foi estimulado por políticas governamentais, embora não diretamente. Em 1964, surgiu o Banco Nacional da Habitação, que tinha como intuito suprir o déficit habitacional brasileiro, no entanto, a criação do Banco fomentou a utilização dos subsídios por parte da camada mais favorecida economicamente, distorcendo a ideia de suprir o déficit habitacional existente no país naquela época, sendo assim, associações e cooperativas habitacionais se organizaram a fim de solucionar o problema de moradia no país (DICKMANN; DICKMANN; MAGRI, 2010).

Dentro da classe de cooperativas habitacionais no Brasil, existem cerca de seis tipologias: Cooperativa Habitacional Fechada; Cooperativa Habitacional Aberta; Cooperativa Habitacional Motivada; Cooperativa Habitacional Autofinanciada, Falsas Cooperativas Habitacionais e Cooperativa Habitacional Autogestionária, que é "organizada a partir das necessidades dos cooperados, por eles gerida (poupança coletiva, compra de área de terra, construção e repasse das moradias a preço de custo)" (DICKMANN, 2013).

Em meados de 1990, surgiu a União Nacional de Moradia Popular (UNMP) que começou a se organizar em prol de criar um programa nacional de habitação através de cooperativas e associações de autogestão. A UNMP entende que para avançar no sistema habitacional é necessário criar uma política de propriedade coletiva, onde "os proprietários das moradias e os titulares do financiamento não seriam mais os beneficiários individuais, mas a Associação ou a Cooperativa" (BARBOSA; PESSINA; RODRIGUES, 2008, p.23-24).

As propostas da UNMP, a respeito da propriedade 
coletiva, tendem para o que Frantz (2012) traz sobre a cooperação moderna que, embora, fruto do modelo capitalista de organização da sociedade, propõe mudanças na forma econômica em que a sociedade está disposta. O novo modelo de cooperação, baseado em um sistema de associações-cooperativas, valoriza o trabalho humano e são "postas a serviço das necessidades e interesses de quem trabalha".

Para Frantz (2012, p. 26),

No espaço das questões sociais, decorrentes do processo técnico e político de trabalho, elaboram-se os conceitos de solidariedade e de cooperação. Nas relações sociais do processo de trabalho dá-se cooperação e solidariedade. Cooperação e solidariedade são práticas sociais.

Logo, a organização cooperativa faz com que os indivíduos interajam entre si, criando laços, despertando solidariedade e responsabilidade por aquilo que é de todos, seja o meio ambiente - ou uma propriedade exclusiva -, e possibilitando o desenvolvimento da humanidade e do espaço onde sua vida acontece (FRANTZ, 2012).

\section{Metodologia}

A pesquisa configura num estudo de caso único numa abordagem qualitativa. Em termo de seus objetivos classifica-se como exploratória e descritiva. Os procedimentos técnicos empregados foram as pesquisas bibliográfica, documental e pesquisa de campo.

A entrevista foi a principal técnica de coleta dos dados empíricos que se deu através de entrevistas semiestruturadas que são as entrevistas que possuem um roteiro pré-estabelecido conforme apresentado nos apêndices. A coleta de dados foi realizada em maio de 2014, as entrevistas se deram em momentos distintos, pessoalmente e por ferramentas da internet, conforme a disponibilidade dos entrevistados. Este tipo de entrevista segue um roteiro prévio, mas permitem algumas interferências do pesquisador, quando necessário (VERGARA, 2008).

Para selecionar os participantes da entrevista, utilizou-se de amostragem intencional que consiste em uma amostragem não probabilística, em que os colaboradores são selecionados a partir dos interesses dos investigadores, como esclarece Oliveira (2001). A esse respeito, contou-se com a colaboração do presidente da Coohabras, o diretor pedagógico e um cooperado.

A análise de conteúdo foi a técnica utilizada para interpretar os dados levantados, segundo Marconi e Lakatos (2010, p. 151) “a análise dos dados é o processo de formação de sentido além dos dados, e esta formação se dá consolidando, limitando e interpretando o que as pessoas disseram e o que o pesquisador viu e leu, isto é, o processo deformação de significado", dessa forma, os dados serão explicados conforme as relações existentes entre o objeto estudado e os demais elementos afetados pela sua existência.

\section{4.. Resultados e Discussões}

Com a finalidade de entender melhor a interação da Coohabras com a sociedade, foi feita a análise do conteúdo coletado, inicializando pelo histórico para demonstrar a evolução desta cooperativa. Em seguida é realizada a análise da interação da cooperativa com a sociedade a partir dos dados coletados e com referência a pesquisa bibliográfica levantada.

\subsection{Histórico}

A Coohabras nasceu em novembro 2010, depois de aproximadamente quatro anos de debate dentro de uma ONG em Veranópolis, onde foi abordado o cooperativismo habitacional do Rio Grande do Sul. Entretanto, havia um limite do poder público para disseminar essa ideia, que precisava ser liberado para levar o projeto à diante, sem que o poder público fosse um elemento vital de ter ou não cooperativas espalhadas.

Começa a modelar uma operação para o Rio Grande do Sul, Santa Catarina e Paraná, que foi discutida no Partido Social Mundial em Janeiro de 2010, com as cooperativas habitacionais da serra gaúcha. Nesse debate foi discutido que é possível acessar e produzir moradias quando organizados em cooperativas, e foi decidido que era viável criar a cooperativa habitacional no Rio Grande do Sul, porém, poderia levar também para o Brasil todo.

A Coohabras nasce desse debate, e onde perceberam estar maduro o suficiente para sair do Rio Grande do Sul e ir para outros estados. Então é instalada em São Paulo em 2011, para que essa operação nacional se encontre no centro do país, ou seja, perto das outras regiões para facilitar a conexão.

São Paulo, atualmente se encontra em déficit habitacional, onde estão com dificuldade em produzir, encontrar terras, organizar pessoas e na região metropolitana tem um grande número de pessoas sem casas. Sendo assim, a Coohabras escolhe São Paulo para colocar seu projeto, a fim de testar o modelo no pior cenário.

A Coohabras conta com algumas vantagens, como não ter concorrentes, ser a única que está disseminando o cooperativismo de habitação, sendo assim, fica fácil ir a uma associação de moradores, a sindicatos e universidades, e apresentar o que a Coohabras está proporcionando, neste sentido, é uma vantagem ser os pioneiros.

Outra vantagem, é que a Cooperativa criou um modelo autossustentável, ou seja, não dependem de recursos externos para levar Coohabras à diante, sendo assim, não são vulneráveis à mudança de presidentes, de governador, de prefeito.

Os cooperados têm a possibilidade de desenhar a própria casa, pois a Coohabras modelou seu projeto a fim de que o cooperado também participe de todo 
o processo, desde a escolha da área até o desenho da engenharia. Torna-se uma vantagem para a Coohabras, pois esse processo participativo só traz cooperados interessados em desenvolver.

A Cooperativa também encontrou algumas dificuldades desde a sua fundação, uma delas é a falta de recursos para dar suporte institucional, principalmente nesses três anos, pois a Coohabras não tinha dinheiro para se auto sustentar, porém, tinha muita coragem para levar o projeto à diante.

Ainda se deparou com a falta de lideres capazes de disseminarem essas informações e desenvolverem o projeto, no Rio Grande do Sul há várias pessoas que conhecem o cooperativismo, porém, não tem conhecimento profundo sobre o cooperativismo habitacional ligado a economia solidária.

Devido à alta quantidade de cooperativas no sul do Brasil, em Santa Catarina, por exemplo, é um dos estados brasileiros que mais contêm cooperativas, e a escassez nos outros estados brasileiros, quando começaram a atuar em outros estados brasileiros, foi preciso explicar para as pessoas como funciona uma cooperativa, pelo fato de se encontrar pessoas que ainda não ter conhecimento o que é e o seu real objetivo, apesar dos princípios cooperativistas terem mais de 200 anos.

\subsection{A cooperativa e a sociedade}

O foco da Coohabras é proporcionar a população do Brasil que não possuem uma moradia digna A cooperativa, portanto, se sustenta nos princípios do cooperativismo que conforme Oliveira (2011), estes princípios devem ser incorporados pelo modelo de gestão, efetuando algumas aplicações em seus significados originais.

Neste sentido, a Coohabras desenvolveu um sistema baseado na participação, na contribuição, na educação e na autogestão. Esses princípios são os pilares da Cooperativa Coohabras em todos os seus programas e projetos de habitação.

A Coohabras busca por meio de seus valores e crenças servir como modelo de organização dentro da sociedade, não apenas como uma cooperativa que luta pelos interesses de seus cooperados apenas, mas busca através de suas atividades um novo modelo de sociedade, mais humano e igualitário.

Para Frantz (2012), é possível mudar o modelo capitalista de organização que a sociedade está sujeita através do cooperativismo. Nesta perspectiva, a Coohabras considera que uma das maiores dificuldades causadas pelo modo de produção capitalista é a sua estruturação, que não comporta a oportunidade a todos os membros da sociedade, por isso, através do modelo de cooperativismo habitacional que a Coohabras adota, principalmente através da autogestão, cria-se a oportunidade de os cooperativados adquirirem seus próprios imóveis a preço de custo, onde eles próprios cuidarão da compra do terreno, contratação de mão de obra, e decidirão as demais questões relacionadas à construção dos imóveis.

Conforme relatado pela diretoria pedagógica da cooperativa, quando se trata de adquirir um imóvel no "mercado comum": "o comprador estará pagando pelo imóvel, mão de obra investida e também pelo lucro do construtor, e esse lucro é que causa as maiores discrepâncias quando se trata do setor habitacional, pois é muito mais do que a maioria da população brasileira consegue pagar".

Mediante seus esforços, a Coohabras busca reduzir basicamente dois problemas: o déficit habitacional no país que até 2012, segundo o IPEA (2013) era de 8,53\% e a falta de oportunidade de se adquirir um imóvel causada pela má distribuição de renda. Além desses problemas, a cooperativa busca estimular uma nova forma de relacionamento social, onde as pessoas possam ajudar umas as outras, viver em condições de maior igualdade e possam questionar-se a respeito da realidade em que vivem.

Os grupos de cooperativados são formados principalmente pela influência de conhecidos, segundo entrevista realizada com um cooperativado. De acordo com o mesmo, o que mais chamou atenção na hora de optar a entrar na cooperativa foi a possibilidade de construir sua casa própria a um preço bem menor que o de mercado. Além disso, o cooperado compartilhou que aderir ao cooperativismo fez com que o mesmo pudesse desenvolver sua capacidade de relacionar-se com outras pessoas e de conviver com opiniões diferentes das suas. Isto confirma a teoria defendida por Frantz (2012), de que a organização cooperativa faz com que os indivíduos interajam entre si, criando laços, despertando solidariedade e responsabilidade por aquilo que é de todos.

Sabe-se que as cooperativas são extremamente importantes para a sociedade onde estão inseridas, como foi o caso de Rochdale, Inglaterra em 1844, que possibilitou que tecelões se reunissem para conseguir comprar e vender mercadorias comuns em maior quantidade e menor preço, e dessa forma pudessem melhorar as suas condições de vida Organização das Cooperativas Brasileiras (OCB).

De acordo com a OCB, nos municípios que possuem cooperativas, o Índice de Desenvolvimento Humano (IDH) local é maior. Segundo o site do IBGE, esse índice é medido em cada município a cada dez anos é correspondente à média de fatores como taxa de escolaridade e alfabetização, renda, expectativa de vida, taxa de natalidade, entre outros elementos que influenciam diretamente a qualidade de vida e bem estar social.

A Coohabras, por ter se instalado na cidade em 2010 ainda não possui nenhum imóvel construído, portanto, de acordo com o presidente da cooperativa em entrevista, não se tem subsídios necessários para medir o quanto a cooperativa contribuiu para que esse índice pudesse ser maximizado, pois em Chapecó o último índice publicado pelo IBGE foi no mesmo ano de iniciação das atividades da cooperativa, 2010, e na época a média correspondia a 0,790 . 
Em se tratando de desenvolver as pessoas que estão dentro da cooperativa, segundo a diretoria pedagógica, a Coohabras procura abordar e entender quais são os papeis dos cidadãos dentro da sociedade através da discussão de assuntos que têm estado bastante em voga, como política, economia e tão importante quanto os demais assuntos, busca-se trabalhar também o desenvolvimento sustentável. Considerando ainda que esse tema é indispensável nas discussões das mais diversas organizações, e nos mais diferentes níveis de organização da sociedade, como nas discussões diárias da sociedade sobre o desenvolvimento dos municípios e das regiões (GONÇALVES, 2005). Desde a década 1980, a ONU - Organização das Nações Unidas tem buscado tratar assuntos relacionados às questões ambientais. Em 1987 , consequentemente às discussões realizadas previamente, foi apresentado um documento que abordou os principais princípios do desenvolvimento sustentável, o Relatório Brundtland, que definia como desenvolvimento sustentável “O desenvolvimento sustentável é o desenvolvimento que encontra as necessidades atuais sem comprometer a habilidade das futuras gerações de atender suas próprias necessidades" (ONU).

Sabendo disso, de acordo com a presidência e diretoria pedagógica: "a cooperativa busca realizar as suas atividades da maneira mais sustentável possível, desde as questões financeiras até a realização de suas construções utilizando materiais que não agridam o ambiente e que possam ser reciclados e reaproveitados.".

Para basear-se cada vez mais no desempenho de suas atividades portados no desenvolvimento sustentável, a Coohabras conta com o apoio de várias organizações que auxiliam, principalmente, através de consultorias, divulgações e discussões. Dentre essas organizações estão Mandalah, Endeavor e Unisol.

\section{Considerações Finais}

O objetivo desta investigação foi compreender como se evidencia a interação da cooperativa habitacional e a sociedade onde ela está inserida com base nos princípios do cooperativismo, chegou-se a algumas constatações que seguem:

A Coohabras desenvolveu um sistema baseado na participação, na contribuição, na educação e na autogestão, esses princípios são os pilares da cooperativa em todos os seus programas e projetos de habitação, que tem a finalidade de proporcionar moradia digna à população do Brasil.

Por meio do modelo de cooperativismo habitacional que a Coohabras adota, principalmente através da autogestão, cria-se a oportunidade de os cooperativados adquirirem seus próprios imóveis a preço de custo, contando com um processo participativo que atrai cooperados interessados em desenvolver.

A formação dos grupos de cooperativados se dá, sobretudo pela influência de conhecidos, sendo que a possibilidade de construir a casa própria a um preço bem menor que o de mercado é o que mais chama a atenção dos associados na visão dos mesmos.

Em relação ao compromisso da cooperativa com o desenvolvimento sustentável evidenciou-se que a Coohabras conta com o apoio de várias organizações que auxiliam nas consultorias, divulgações e discussões para realizar as suas atividades da maneira mais sustentável possível, desde as questões financeiras até a realização de suas construções utilizando materiais que não agridam o ambiente e que possam ser reciclados e reaproveitados.

O déficit habitacional e a falta de oportunidade de se adquirir um imóvel causada pela má distribuição de renda são problemas que a Coohabras tem o objetivo de reduzir. Além disso, a cooperativa busca estimular uma nova forma de relacionamento social, onde as pessoas possam ajudar umas as outras, viver em condições de maior igualdade e possam questionar-se a respeito da realidade em que vivem.

O presente estudo se limitou a compreender como se manifesta a interação da Coohabras e a sociedade onde ela está inserida com base nos princípios do cooperativismo. Apesar de ter proporcionado conhecimento e experiências importantes, novas indagações surgiram possibilitando a realização de novas pesquisas. Sugere-se assim que sejam realizados estudos futuros que contemplem comparações com outras cooperativas habitacionais e também pesquisas mais aprofundadas com a finalidade analisar como essa forma de cooperação contribui para o IDH, identificando quais fatores são determinantes para proporcionar a elevação desse índice.

\section{Referências}

BARBOSA, Benedito Roberto; PESSINA, Leonardo; RODRIGUES, Evaniza. Produção social da moradia: desafios da política de habitação. Revista Proposta. Rio de Janeiro: Fase, no 116, p. 21-25, 2008.

BLOG SICOOB. Mercado Cooperativista: A influência do cooperativismo para o desenvolvimento da sociedade. Disponível em: <http://www.blogsicoob. com.br/noticias/mercado-cooperativista/279a-influencia-do-cooperativismo-para-odesenvolvimento-da-sociedade> Acesso em: 23/04/2014.

BRASIL. Código civil. Congresso Nacional. Disponível em: <http://www.planalto.gov.br/ ccivil_03/leis/2002/110406.htm> Acesso em: 09/10/2014.

BRASIL COOPERATIVO. Cooperativismo: forma 
ideal de organização. Disponível em: <http://www. brasilcooperativo.coop.br/site/cooperativismo/ index.asp> Acesso em: 23/04/ 2014.

BRÜSEKE, Franz Josef. O problema do desenvolvimento sustentável. In. CAVALCANTI, C. (org.). Desenvolvimento e natureza: estudos para uma sociedade sustentável. 5 ed. São Paulo: Cortez, 2009.

CARVALHO, Adriano Dias de. O cooperativismo sob a ótica da gestão estratégica global. Disponível em: $<$ http://books.google.com.br/books?id=9NezSINp pmsC\&printsec $=$ frontcover\&dq $=$ cooperativismo\& $\mathrm{hl}=\mathrm{pt}-B R \& s a=X \& \mathrm{ei}=2 \mathrm{MlfU}-3 \mathrm{UJc} X \mathrm{~s} 2 \mathrm{Q} X \mathrm{HxICQCg \&}$ ved $=0 C D k Q 6 A E w A A \# \mathrm{v}=$ onepage $\& \mathrm{q}=$ ideiais $\% 20$ $\& f=$ false $>$ Acesso em: 25/04/2014.

CASTELO, Dora Bussab. Cooperativas e associações habitacionais. Revista de Direito Imobiliário. Editora Revista dos Tribunais, n. 46, p.134-182, jun. 1999.

SCHMIDT, Derli; PERIUS, Vergílio. Cooperativismo e cooperativa. In: CATTANI, Antonio David (org.). A outra economia. Porto Alegre: Veraz, 2003.

CMMA. Nosso futuro comum. Rio de Janeiro: Fundação Getúlio Vargas, 1988.

DICKMANN, Ivanio; DICKMANN, Ivo. Manual do cooperativado. São Paulo: Coohabras, 2011.

DICKMANN, Ivanio; DICKMANN, Ivo; MAGRI, Cledir. Construindo cidadania: cooperativas de habitação, política pública e educação popular. Passo Fundo: Battistel, 2011.

DICKMANN, Ivanio. Cooperativas habitacionais no Brasil In: Conferência Regional das Américas, São Paulo 6-8 out. 2013.

Energia, Ambiente e Desenvolvimento. Caderno digital de informação sobre energia, ambiente e desenvolvimento Disponível em: <http:// ambientes.ambientebrasil.com.br/gestao/artigos/ desenvolvimento_sustentavel.html> Acesso em: 22/04/2014.

FRANTZ, W. Associativismo, cooperativismo e economia solidária. Ijuí: Editora Unijuí, 2012.

GONÇALVES, D. Revista espaço acadêmico: Desenvolvimento sustentável: o desafio da presente geração. - № 51, 2005. Disponível em: <http:// www.espacoacademico.com.br/051/51goncalves. htm> Acessado em: 07/07/2014
JESUS, Paulo de; TIRIBA, Lia. Cooperação. In: CATTANI, Antônio David (Org.). A outra economia. Porto Alegre: Veraz Editores, 2003.

LOURENÇO, Nielson Polucena; LUNA, Flávio Melo de; SOUSA; Joceia Gouveia de. Cooperativismo, cooperação e território: um estudo de caso na Coopapi em Apodi - RN, Brasil. Disponível em: <http://www.egal2013.pe/wp-content/ uploads/2013/07/Tra_Nielson-PolucenaLouren\%C3\%A7o-Fl\%C3\%A1vio-Melo-deLuna-Joceia-Gouveia-de-Sousa.pdf $>$ Acesso em: 19/04/2014.

MARCONI, Marina de Andrade; LAKATOS, Eva Maria. Fundamentos da metodologia científica. 7ed. São Paulo: Editora Atlas, 2010.

MENDES, Armando Dias. Envolvimento e desenvolvimento: introdução à simpatia de todas as coisas. In: CAVALCANTI, C. (org.). Desenvolvimento e natureza: estudos para uma sociedade sustentável. 5ed. São Paulo: Cortez, 2009.

OCB. Cooperativismo: forma ideal de organização. Disponível em: <http://www.ocb.org.br/site/ cooperativismo/> Acessado em: 09/10/2014.

OCB. Princípios: Sete linhas orientam o cooperativismo. Disponível em: <http://www. ocb.org.br/site/cooperativismo/principios.asp> Acessado em: 09/10/2014.

OLIVEIRA, Djalma de Pinho Rebouças de. Manual de gestão das cooperativas: uma abordagem prática. 5 ed. São Paulo: Atlas, 2011.

RIOS, Gilvando Sá Leitão. Cooperação e tipos de cooperativismo no Brasil. Disponível em:<http:// tupi.fisica.ufmg.br/ michel/docs/Artigos_e_ textos/Gestao_de_cooperativas/tipos $\% 20 \mathrm{de} \% 20$ cooperativismo.pdf

> Acesso em: 19/04/2014.

SEBRAE. Cultura da cooperação: série empreendimentos coletivos. Disponível em: $<\mathrm{http}: / /$ www.cbn.org.br/redemi/download/cultura_de_ cooperacao_sebrae.pdf> Acesso em: 19/04/2014.

SICOOB Blucredi. História do cooperativismo. Programa Cooperação, 2013 (microfilme).

VERGARA, Sylvia Constant. Métodos de pesquisa em administração. 3. ed. São Paulo: Atlas, 2008. 
APÊNDICE A - ROTEIRO DE ENTREVISTA A PRESIDÊNCIA

1. O que você considera ser a coisa mais importante já feita pela Coohabras?

2. De que forma você descreveria a Coohabras como um mecanismo de transformação social?

3. Qual o propósito da Coohabras como instituição cooperativa?

4. Quais são os principais problemas enfrentados pela Cooperativa no(s) ambiente(s) onde ela está inserida?

5. Breve histórico sobre a Coohabras

6. Quais são os planos para o futuro da Cooperativa?

7. Como você descreveria a relação entre a Coohabras e o Modo de Produção vigente?

8. Você vê a Coohabras como um fator contribuinte para o desenvolvimento sustentável? Quais são as principais maneiras que a Cooperativa contribui para o Desenvolvimento Sustentável?

\section{APÊNDICE B - ROTEIRO DE ENTREVISTA A DI- RETORIA PEDAGÓGICA}

1. Qual o papel da educação no movimento cooperativo?

2. Quais os principais métodos educacionais adotados pela Cooperativa?

3. Como a educação contribui para a manutenção e renovação (atualização) da Cooperativa?

4. Como você descreveria a relação entre a Coohabras e o Modo de Produção vigente? Qual a sua análise sobre essa relação?

5. Como o Modo de Produção a que estamos submetidos influencia a relação educador, cooperador e cooperativa?

6. Quais são as principais dificuldades e facilidades enfrentadas ao desempenhar as atividades designadas ao seu setor (diretoria pedagógica)?

7. Você vê a Cooperativa como instrumento que possibilita o Desenvolvimento Sustentável e Humano (IDH)? Quais são os pontos na Cooperativa onde esse Desenvolvimento é melhor notado?

8. Como educador, quais são as suas perspectivas em relação ao futuro do Cooperativismo Habitacional no Brasil e de que forma você acha que seria possível alcançar isso?

\section{APÊNDICE C - ROTEIRO DE ENTREVISTA AO COOPERADO}

1. Quais as razões e motivações que o levou a associar a Coohabras?

2. Quais os principais impactos da Coohabras na sua vida?

3. Como começou a sua "caminhada" junto à Cooperativa e quais foram as principais dificuldades e facilidades enfrentadas?

4. Como você vê o Cooperativismo em sua vida, família, trabalho, círculo social?

5. Como você conheceu a Coohabras?

6. O que te motivou a tornar-se um cooperativado junto à Coohabras?

7. Antes de conhecer a Coohabras, você já conhecia o Cooperativismo? Quais eram as suas principais dúvidas?

8. Você vê a Coohabras como um instrumento capaz de transformar a sociedade?

9. Quais são as suas perspectivas em relação a Coohabras?

10. Desde que você se tornou um cooperativado, quais foram os seus maiores aprendizados adquiridos?

11. O que você considera mais importante em relação à Coohabras para a sua vida? 